\title{
Aproveitamento de torta do tabaco gerado na produção de biodiesel para a obtenção de bioplástico
}

\author{
Larissa Brixner Riçal \\ Leonardo Bastos Moraes ${ }^{2}$ \\ Diego de Souza ${ }^{3}$ \\ Rosana de Cássia de Souza Schneider ${ }^{4}$ \\ Maria Viviane Gomes Müller ${ }^{5}$
}

\begin{abstract}
RESUMO
O poli 3-hidroxibutirato - $\mathrm{P}(3 \mathrm{HB})$ - é o principal polímero da classe dos poli hidroxialcanoatos (PHAs), polímeros biodegradáveis sintetizados por microrganismos a partir de diversos substratos. $\mathrm{O}$ objetivo desse trabalho foi a produção de $\mathrm{P}(3 \mathrm{HB})$ a partir do resíduo da extração do óleo da semente de tabaco (Nicotiana tabacum L.) como substrato alternativo e de baixo custo para triagem de microrganismos produtores de $\mathrm{P}(3 \mathrm{HB})$. O resíduo foi avaliado quanto a sua composição e beneficiado através de hidrólise. $\mathrm{O}$ hidrolisado foi utilizado em ensaio de fermentação com cepas bacterianas isoladas da Estação de Tratamento de Efluentes (ETE) da Universidade de Santa Cruz do Sul (UNISC). Para visualização de inclusões lipofílicas nas células, indicadoras de acúmulo de $\mathrm{P}(3 \mathrm{HB})$, utilizou-se coloração de Sudan Black. A extração do polímero do interior das células foi realizada utilizando-se clorofórmio e hipoclorito de sódio e o produto extraído foi analisado em espectrofotômetro. De 25 isolados, a cepa E10 foi a que apresentou melhor resultado frente à coloração de Sudan Black. A análise do produto obtido sugere que a E10 produziu PHAs utilizando o resíduo de tabaco, demonstrando seu potencial como substrato de baixo custo para crescimento microbiano e obtenção de biopolímeros.
\end{abstract}

Palavras-chave: Poli 3-hidroxibutirato. P(3HB). Biopolímero. Torta de tabaco.

\begin{abstract}
Poly 3-hydroxybutyrate - $\mathrm{P}(3 \mathrm{HB})$ - is the main polymer of the class of poly hydroxyalkanoates (PHAs), biodegradable polymers synthesized by microorganisms from various substrates. This work aims to produce $\mathrm{P}(3 \mathrm{HB})$ from the tobacco seed (Nicotiana tabacum L.) oil extraction waste as an alternative and low cost substrate for screening microorganisms producing $\mathrm{P}(3 \mathrm{HB})$. The residue was evaluated for its composition and processed by hydrolysis. The hydrolyzate was used in fermentation assays with bacterial strains isolated from the Wastewater Treatment Plant (WWTP) of Universidade de Santa Cruz do Sul (UNISC). Sudan Black staining was used to visualize the cell lipophilic inclusions, $\mathrm{P}(3 \mathrm{HB})$ accumulation indicators.

\footnotetext{
${ }^{1}$ Aluna do Curso de Química Industrial da Universidade de Santa Cruz do Sul - UNISC. 2 Mestrando do Programa de Pós-Graduação em Tecnologia Ambiental da Universidade de Santa Cruz do Sul.

3Professor do Programa de Pós-Graduação em Tecnologia Ambiental na Universidade de Santa Cruz do Sul.

${ }^{4}$ Professora do Departamento de Química e Física e do Programa de Pós-Graduação em Tecnologia Ambiental na Universidade de Santa Cruz do Sul. ${ }^{5}$ Professora do Departamento de Biologia e Farmácia e do Programa de Pós-Graduação em Tecnologia Ambiental na Universidade de Santa Cruz do Sul.<mmuller@unisc.br>
} 
The extraction of the polymer inside the cells was performed using chloroform and sodium hypochlorite and the product was analyzed using a spectrophotometer. From 25 isolates, only E10 strain was positive for Sudan Black staining. The analysis of the product suggests that E10 produces PHAs using tobacco residue, showing its potential as a low cost substrate for microbial growth and acquisition of biopolymers.

Keywords: Poly 3-hydroxybutyrate. P(3HB). Biopolymer. Tobacco cake.

\section{INTRODUÇÃO}

$\mathrm{O}$ poli 3-hidroxibutirato $-\mathrm{P}(3 \mathrm{HB})$ - é o polímero mais abundante dentre à classe dos poli hidroxialcanoatos (PHAs) (PAL et al, 2009). Os PHAs são biopolímeros biodegradáveis que podem ser obtidos de bactérias e outros microrganismos (DESOUKY et al., 2014). Bactérias acumulam intracelularmente $\mathrm{P}(3 \mathrm{HB})$ na forma de corpos lipofílicos como reserva energética quando expostas a meio com restrições de nutrientes (sobretudo nitrogênio), porém quando há grande disponibilidade de carbono (SUDESH et al., 2000).

Os PHAs têm ganhado destaque devido a sua biodegradabilidade, tornando-os bons candidatos para substituir os plásticos convencionais, não biodegradáveis, derivados do petróleo (CIESIELSKI et al., 2015). Contudo, uma grande desvantagem para a comercialização dos PHAs, bem como sua consolidação no mercado, é o alto custo de produção se comparado aos plásticos convencionais (SINGH et al., 2015).

O preço do substrato é um dos fatores que mais influencia no custo total de produção do $\mathrm{P}(3 \mathrm{HB})$ (CHOI e LEE, 1997). Fontes de carbono purificadas, como glicose, sacarose, maltose, entre outras, podem representar mais de $30 \%$ do custo total de todo o processo produtivo (LOPES et al., 2009; SERAFIM et al., 2008). Dessa maneira, tem se buscado substratos que possuam baixo valor, mas que mantenham a taxa de produção muito próxima ou superior das obtidas com fontes de carbono convencionais (PAL et al., 2009).

No lugar das fontes de carbono usuais, os resíduos agroindustriais podem ser uma alternativa interessante, uma vez que não demandam área para produção (SOMLEVA et al., 2013). Além disso, o aproveitamento de resíduos desprezados após o processamento reduz significativamente o impacto ambiental gerado pela atividade agroindustrial (LIAO et al., 2014; MAITY, 2015).

O presente trabalho busca a prospecção de microrganismos com alta taxa de crescimento microbiano, bem como acumulação de PHAs, utilizando como fonte 
alternativa de carbono o hidrolisado da torta de tabaco, gerada a partir da produção de biodiesel, para obtenção de $\mathrm{P}(3 \mathrm{HB})$.

\section{FUNDAMENTAÇÃO TEÓRICA}

Os PHAs formam uma classe de compostos orgânicos lipofílicos sintetizados em grande quantidade por algumas bactérias em situações de estresse ambiental e fisiológico (STEINBÜCHEL e VALENTIN, 1995). Já foram encontrados pelo menos 150 tipos de unidades monoméricas dos PHA's - ácidos hidroxialcanóicos (HAs) sendo os mais comuns o hidroxibutirato (HB), hidroxivalerato (HV), hidroxipropionato (HP) e o hidroxihexanoato (HHx) (MENG et al., 2014; STEINBÜCHEL e VALENTIN, 1995).

Nas bactérias, a síntese de PHAs pode envolver muitas enzimas, dependendo da via metabólica que será ativada e dos monômeros que serão polimerizados; já são conhecidas 45 enzimas e 12 rotas (MENG et al., 2014). A principal via de formação de PHAs envolve pelo menos três enzimas: PhaA ( $\beta$-cetoacil-CoA tiolase), PhaB (acetoacetil-CoA redutase/desidrogenase, dependente de NADPH) e PhaC (PHAsintase) (JENDROSSEK e PFEIFFER, 2014). As PhaC, formadas por quatro classes de enzimas, são as mais importantes do processo, sendo responsáveis pela polimerização dos HAs para a formação de grânulos de PHAs, normalmente encontrados junto à membrana plasmática (JENDROSSEK e PFEIFFER, 2014; PRIETO et al., 2015; SINGH et al., 2015).

Alterações de temperatura e $\mathrm{pH}$, disponibilidade de oxigênio, carência de nutrientes como fósforo e nitrogênio, e excesso de fontes de carbono são algumas das condições que levarão a célula a sintetizar PHAs, que servem principalmente como reserva energética (DOUDOROFF e STANIER, 1959; REDDY, 2003; TAN et al., 2014).

Os PHAs se assemelham a polímeros sintéticos como o polipropileno e o polietileno de alta densidade, porém possuem características físico-químicas únicas, como a resistência à tração, a temperatura de fusão elevada e a baixa temperatura de transição vítrea (SUDESH et al., 2000). Essas características fazem dos PHAs grandes candidatos para substituir os plásticos derivados do petróleo (CIESIELSKI, et al., 2015; LEGAT, et al., 2010). Contudo, os custos de produção elevados, o processo de extração e as dificuldades para remover impurezas são desafios que permeiam a sua aplicação de forma mais ampla (SOMLEVA et al., 2013). 
Choi e Lee (1997) realizaram análise de processos e avaliação econômica para produção de $\mathrm{P}(3 \mathrm{HB})$ em escala industrial. Considerando-se uma produção anual de 2500 toneladas de $\mathrm{P}(3 \mathrm{HB})$, utilizando-se uma cepa geneticamente modificada de Escherichia coli com taxa de acumulação de 77,3\% quando glicose foi utilizada como fonte de carbono, o custo anual de produção era de aproximadamente U\$ 17.488.000, sendo U\$ 5.369.000 oriundos somente da fonte de carbono (valores de 1996). Desconsiderando-se o custo de venda e margem, o preço por quilo de $\mathrm{P}(3 \mathrm{HB})$ seria de U\$ 6,14. Porém, ao se trocar a fonte de carbono de glicose (U\$ 0,5/kg; 1996) para amido de milho hidrolisado (U\$ 0,2/kg; 1996), o custo de produção por quilo de $\mathrm{P}(3 \mathrm{HB})$ cai cerca de 20\% - U\$ 5,00/kg (CHOI e LEE, 1997).

Nas diversas estratégias apontadas pela literatura para reduzir o custo de produção dos PHAs são encontrados pontos em comum como a triagem de microrganismos com altas taxas de acumulação de PHAs, substratos de baixo custo e otimização do processo de fermentação escolhido (KHANNA e SRIVASTAVA, 2005; CHOI e LEE, 1999).

A utilização de resíduos agroindustriais como fontes de carbono tem sido apontada como uma das melhores alternativas na viabilização da produção em larga escala de PHAs (CEYHAN e OZDEMIR, 2011; SUKAN et al., 2014). Altas taxas de acúmulo de PHAs utilizando-se esse tipo de resíduo já foram reportadas. A cepa bacteriana E. coli $\mathrm{K} 24 \mathrm{~K}$ obteve $72,9 \%$ de acúmulo utilizando-se milhocina como fonte de carbono (NIKEL, et al., 2006). Uma cepa de Haloferax mediterranei chegou a acumular $70 \%$ de seu peso seco em PHAs tendo como substrato a vinhaça, resíduo da indústria de álcool de difícil disposição devido ao $\mathrm{pH}$ ácido e características poluentes (BHATTACHARYYA, et al., 2012). As cepas Bacillus flexus ME-77, Pseudomonas corrugata 388 e Bacillus subtilis OK2 obtiveram 51, 42 e 40\% de PHA/célula quando melaço de cana de açúcar, resíduos da produção de biodiesel à base de soja e casca de laranja, respectivamente, foram empregados como substratos (ASHBY, et al., 2004; SUKAN, et al., 2014; EL-SHEEKH, et al., 2015).

Para identificar o acúmulo de PHAs pela bactéria, são empregados, em grande parte, métodos colorimétricos. Devido a sua característica lipofílica, os PHAs são facilmente corados utilizando-se corantes lipossolúveis (WILLIAMSON e WILKINSON, 1958). A coloração de Sudan Black é bastante utilizada para essa finalidade, conferindo aos grânulos de PHAs cor escura de fácil visualização em microscópios ópticos (MESQUITA et al., 2015). 
Outras técnicas muito utilizadas são as colorações por Nile Red ou por Nile Blue, corantes que, quando expostos a luz ultravioleta, fazem com que os grânulos fiquem fluorescentes (OSTLE e HOLT, 1982). Os corantes Nile Red e Nile Blue também são utilizados para identificar PHAs por espectroscopia de fluorescência e microscopia eletrônica de transmissão (BERLANGA et al., 2010).

Os métodos mais usuais de extração dos PHAs acumulados no interior da célula bacteriana são as extrações com solventes, como clorofórmio e acetona, e digestão com hipoclorito de sódio (MIKKILI et al., 2014). Seguido desses, são empregados o tratamento com enzimas; surfactantes, como SDS (dodecil sulfato de sódio); quelantes, como EDTA (ácido etilenodiamino tetra-acético) (KUNASUNDARI e SUDESH, 2011); e rompimento mecânico, como sonicação (XU et al., 2010).

Para caracterização do polímero obtido podem ser empregadas diversas técnicas analíticas, como: Espectroscopia de Infravermelho com Transformada de Fourier (FTIR) (XU et al., 2010); Ressonância Magnética Nuclear (RMN) (SLATER et al, 1999; HAYWOOD et al, 1990); Cromatografia Líquida de Alta Eficiência (HPLC) (SCANDOLA et al., 1997); Cromatografia Gasosa acoplada a Espectrometria de Massa (GC-MS) (ASHBY et al., 2004); e por métodos cristalográficos como Difração de Raios-X (SCANDOLA et al., 1997) e Calorimetria Exploratória Diferencial (DSC) (XU et al., 2010).

\section{MATERIAIS E MÉTODOS}

\subsection{Isolamento e triagem de cepas bacterianas}

Para o isolamento de bactérias com capacidade de acumular $\mathrm{P}(3 \mathrm{HB})$ foi realizada a técnica de esgotamento do material coletado na Estação de Tratamento de Efluentes da UNISC - ETE, em placas de ágar nutriente. Estas foram incubadas a $28^{\circ} \mathrm{C}$ por até 72 horas. Os morfotipos de colônias que surgiram nas placas foram repicados até obtenção de colônias axênicas de cada bactéria. A pureza foi avaliada através de coloração de Gram. Cada isolado recebeu um código de identificação, sendo a letra "E" e um número corrente de acordo com a ordem de isolamento.

As bactérias assim selecionadas foram submetidas ao ensaio de fermentação, descrito abaixo, para verificar aquelas com melhor potencial para produção do biopolímero utilizando o hidrolisado de torta de sementes de tabaco como fonte de carbono. 


\subsection{Composição centesimal da torta de tabaco}

De forma a determinar a composição centesimal da torta de tabaco, e com isso, o potencial de sua empregabilidade como substrato energético, foram seguidas as metodologias de Cecchi (2003).

\subsection{Hidrólise da torta de tabaco}

Como forma de disponibilizar os nutrientes presentes no substrato escolhido, realizou-se uma hidrólise ácida seguindo a metodologia descrita por Pattra et al. (2008). Foram adicionados $1 \mathrm{~L}$ de solução $10 \%$ de $\mathrm{H}_{2} \mathrm{SO}_{4}(\mathrm{v} / \mathrm{v})$ a $150 \mathrm{~g}$ de torta de tabaco, em frasco com tampa de rosca. A mistura foi autoclavada à $121^{\circ} \mathrm{C}, 1$ atm, durante 30 minutos. A mistura foi filtrada e, na sequência, neutralizada com $500 \mathrm{~mL}$ de solução de $\mathrm{KOH} 2 \mathrm{~mol} \mathrm{~L}^{-1}$. O hidrolisado foi mantido sob refrigeração até utilização.

\subsection{Triagem de bactérias usando hidrolisado da torta de tabaco}

A triagem das bactérias acumuladoras de $\mathrm{P}(3 \mathrm{HB})$ foi realizada através de um ensaio de fermentação utilizando o hidrolisado da torta de sementes de tabaco como fonte de carbono. As cepas bacterianas utilizadas neste experimento foram previamente cultivadas em caldo BHI, por 12 - 36 horas a $30^{\circ} \mathrm{C}$. Transcorrido este tempo, foi realizada a padronização do inóculo em espectrofotômetro (FEMTO ${ }^{\text {TM }}$ Espectrofotômetro 700 Plus), em modo de transmitância, 600 nm. De cada um destes cultivos, foram transferidos $100 \mu \mathrm{L}$ e inoculados em erlenmeyers de $250 \mathrm{~mL}$, em triplicata, em meio composto por $35 \mathrm{~mL}$ de solução salina de Bushnell-Hass $\left(1,0 \mathrm{~g} \mathrm{~L}^{-1}\right.$ de $\mathrm{NH}_{4} \mathrm{NO}_{3} ; 1,0 \mathrm{~g} \mathrm{~L}^{-1}$ de $\mathrm{K}_{2} \mathrm{HPO}_{4} ; 1,0 \mathrm{~g} \mathrm{~L}^{-1}$ de $\mathrm{KH}_{2} \mathrm{PO}_{4} ; 0,2 \mathrm{~g} \mathrm{~L}^{-1}$ de $\mathrm{MgSO}_{4} .7 \mathrm{H}_{2} \mathrm{O}$; $0,05 \mathrm{~g} \mathrm{~L}^{-1}$ de $\left.\mathrm{FeCl}_{3} ; \mathrm{pH} 7,0\right)$ e $35 \mathrm{~mL}$ de solução $1: 1$ de peptona e glicose. Os erlenmeyers foram mantidos sob agitação de $150 \mathrm{rpm}$ por 12 horas, a $28^{\circ} \mathrm{C}$.

Decorridas 12 horas de experimento, $30 \mathrm{~mL}$ do hidrolisado da torta de tabaco foram adicionados a cada um dos erlenmeyers os quais foram mantidos nas mesmas condições até completar 24 horas de fermentação. No erlenmeyer para controle positivo foram adicionados $30 \mathrm{~mL}$ de solução $0,5 \mathrm{~mol} \mathrm{~L}^{-1}$ de glicose no lugar de hidrolisado de torta de tabaco.

Nos tempos $0,2,4,6,12$, e 24 horas foram retiradas alíquotas para determinação da biomassa microbiana em espectrofotômetro (FEMTO $^{\text {TM }}$ Espectrofotômetro 700 Plus), em modo de transmitância a $600 \mathrm{~nm}$ e avaliação do parâmetro $\mathrm{pH}$. 
Posteriormente ao tempo de incubação, esfregaços de cada isolado foram preparados em lâminas de vidro e avaliados através da coloração de Sudan Black, conforme metodologia descrita por Legat et al. (2010). Para visualização das lâminas foi utilizado um microscópio óptico (Nikon ${ }^{\circledR}$ Eclipse E200) com aumento de 1000x.

\subsection{Extração do $\mathbf{P}(3 \mathrm{HB})$ da bactéria}

A cepa bacteriana que apresentou maior quantidade de corpos lipofílicos observados através das lâminas de Sudan Black, sendo sua presença relacionada diretamente ao acúmulo de $\mathrm{P}(3 \mathrm{HB})$ e outros PHAs foi submetida ao processo de extração.

Para a extração do polímero do interior da bactéria foi utilizada a metodologia descrita por Xu et al. (2010). Os cultivos de 24 horas, obtidos conforme descrito em 3.4 foram centrifugados a $3600 \mathrm{rpm}$ por 15 minutos. Cada pellet foi então ressuspendido em $100 \mathrm{~mL}$ de clorofórmio e $100 \mathrm{~mL}$ de solução 1:1 hipoclorito de sódio/água, mantidos sob agitação, a $30^{\circ} \mathrm{C}$ por 90 minutos. Transcorrido esse tempo, esta mistura foi transferida para funis de separação onde a fase orgânica - fase em que se encontra o $\mathrm{P}(3 \mathrm{HB})$ - foi separada da fase aquosa.

A água residual da extração foi removida com sulfato de magnésio anidro e o clorofórmio foi removido por rotaevaporação a pressão reduzida. Finalmente foram adicionados $10 \mathrm{~mL}$ de éter de petróleo e clorofórmio (9:1) ao frasco, sendo este acondicionado em capela para evaporação dos solventes, permitindo a formação de um filme polimérico.

\subsection{Análises do polímero através de espectrofotômetro}

A análise do produto extraído como sendo o polímero $\mathrm{P}(3 \mathrm{HB})$ foi realizada por espectrometria. Para determinar o perfil do padrão, uma solução de $10 \mathrm{mg} \mathrm{mL}^{-1}$ de padrão $\mathrm{P}(3 \mathrm{HB})$ (Sigma-Aldrich $^{\circledR}$ ) foi lida em espectrofotômetro (Thermo Scientific ${ }^{\mathrm{TM}}$ NanoDrop 2000c) no modo de varredura. O mesmo foi realizado com a fase orgânica da extração de $\mathrm{P}(3 \mathrm{HB})$ dos cultivos. Os dados obtidos foram tabulados para obtenção de um espectro das amostras frente ao padrão. 


\section{RESULTADOS E DISCUSSÃO}

\subsection{Isolamento e triagem de cepas bacterianas}

Foram obtidas 25 cepas bacterianas oriundas da ETE da UNISC. Seis cepas, denominadas E5, E10, E12, E24 e E25, tiveram crescimento em hidrolisado da torta de tabaco. A cepa E10, bacilo Gram positivo, foi a que apresentou maior acumulo de inclusões lipofílicas, evidenciadas pela coloração de Sudan Black (Figura 1).

Nossos resultados reportam o trabalho de Desouky et al. (2014), onde foi realizada a triagem de bactérias de solo para produção de PHAs através da coloração de Sudan Black. Além, no trabalho de Pal et al. (2009) a coloração de Sudan Black foi utilizada para avaliar o acúmulo de $\mathrm{P}(3 \mathrm{HB})$ pela bactaria Baccilus thuringiensis em crescimento bifásico.

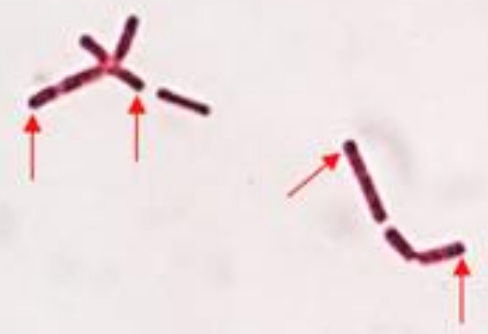

Figura 1 - Detalhe de lâmina de microscopia da bactéria E10 por coloração de Sudan Black: grânulos escuros sugestivos de $\mathrm{P}(3 \mathrm{HB})$ no interior da célula bacteriana (como indicados pelas setas vermelhas).

\subsection{Composição centesimal da torta de tabaco}

Os resultados da composição centesimal da torta de tabaco estão relacionados na Tabela 1. Podemos observar uma média geral de 36,39\% de carboidratos, 31,94\% de proteínas, $27,05 \%$ de lipídeos e 4,50\% de cinzas. Nossos resultados vão de acordo com o descrito por Rossi et al. (2013), onde os autores encontraram valores de 33,05\% para proteínas, $5,05 \%$ para cinzas e $23,15 \%$ de carboidratos.

Tabela 1 - Resultados das análises para composição centesimal.

\begin{tabular}{ccccc}
\hline Amostras & Cinzas & Proteínas & Carboidratos & Lipídios \\
1 & 4,49 & 32,14 & 39,20 & 24,10 \\
2 & 3,87 & 26,25 & 35,72 & 33,94 \\
3 & 5,16 & 37,45 & 34,27 & 23,11 \\
Média \% & 4,50 & 31,94 & 36,39 & 27,05 \\
\hline
\end{tabular}

Na composição do resíduo da torta de tabaco utilizado neste trabalho tivemos os carboidratos como o componente principal, num valor de $36,39 \%$. Este resultado faz com que a torta de tabaco possa ser utilizada como fonte de carbono para obtenção de 
biopolímeros como o $\mathrm{P}(3 \mathrm{HB})$ produzido por microrganismos (ALBUQUERQUE et al., 2011; ALBUQUERQUE et al., 2013; REDDY et al., 2003; HAYWOOD et al., 1990; RAMACHANDRAN et al., 2007).

A partir dos resultados da análise centesimal foi realizada a hidrólise da torta de tabaco. Com este procedimento podemos biodisponibilizar até $90 \%$ do substrato como moléculas metabolizáveis por bactérias (SANTIMANO et al., 2009).

\subsection{Hidrólise da torta de tabaco}

Na Figura 2 A temos a fotografia da torta de tabaco antes da hidrólise, a qual apresenta coloração escura e granulometria variada. A hidrólise da torta de sementes de tabaco resultou em um líquido escuro, levemente viscoso, turvo e de cheiro forte (Figura 2 B). Observou-se também a formação de um sobrenadante na parte superior do frasco, de natureza lipídica, quando o hidrolisado era deixado em repouso e refrigeração, possivelmente sendo atribuído aos ácidos graxos liberados na hidrólise (SCHUCHARDT et al., 1998; HAAS, 2005).

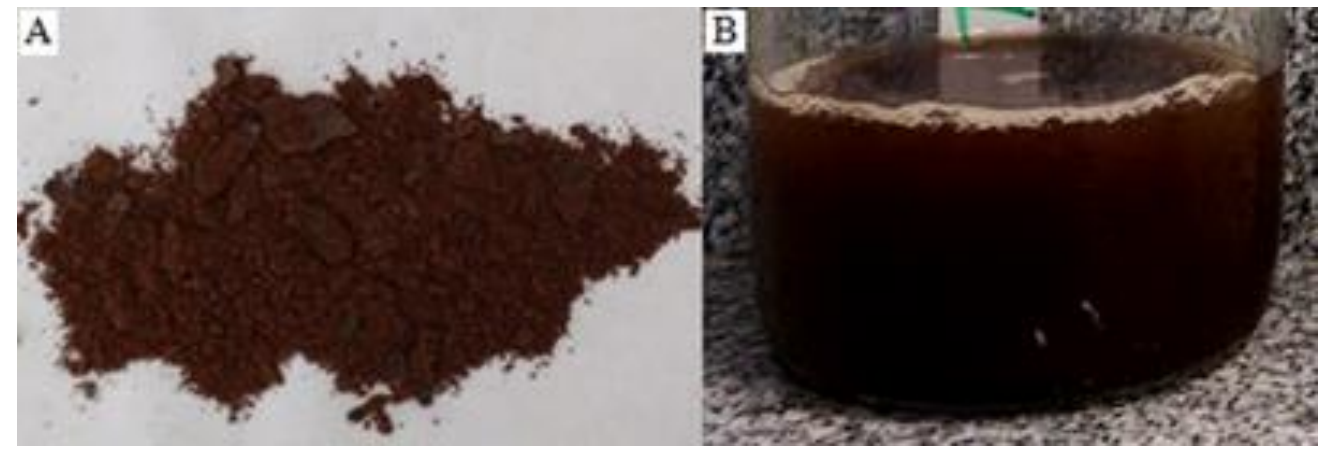

Figura 2 A e B - Hidrólise da torta de tabaco: antes (A), torta de tabaco bruta, e depois (B), o filtrado da hidrólise.

\subsection{Triagem de bactérias usando hidrolisado da torta de tabaco}

Conforme observado no gráfico da Figura 3, podemos verificar que a cepa E10 apresentou nas primeiras 12 horas um crescimento exponencial, transcorrido este tempo verifica-se uma desaceleração de crescimento. De acordo com Doudoroff e Stanier (1959) e Valappil et al. (2007) este fato pode estar relacionado a liberação de compostos tóxicos liberados pela bactéria durante a produção de $\mathrm{P}(3 \mathrm{HB})$. 


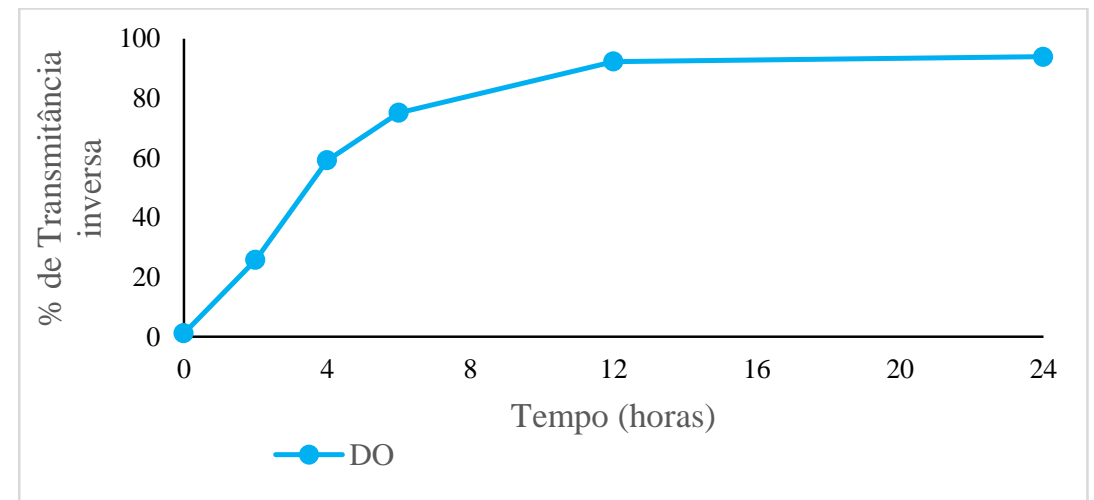

Figura 3 - Curva de crescimento do isolado E10 cultivado em meio contendo hidrolisado de torta de sementes de tabaco, obtida através dos valores inversos de Transmitância das amostras coletadas nos distintos tempos.

\subsection{Extração do $\mathbf{P}(3 \mathrm{HB})$ da bactéria}

O processo de extração do biopolímero produzido pela bactéria E10 foi efetivo, conforme podemos visualizar nas Figuras 4 C e D. Durante o processo de extração foi possível observar uma diferença entre as fases orgânicas, onde a referente ao controle positivo possuía coloração esbranquiçada e a do cultivo suplementado com hidrolisado de tabaco possuía coloração branca muito opaca e aspecto leitoso, como mostram as Figuras 4 A e B.

Nas Figuras $4 \mathrm{C}$ e D podemos observar, visualmente, uma diferença de material polimérico obtido ao final do processo de extração. Na Figura $4 \mathrm{C}$ temos o filme polimérico obtido quando a bactéria usou como substrato glicose. Quando a comparamos visualmente com a Figura $4 \mathrm{D}$, verificamos uma maior formação do biopolímero, aparentemente mais íntegro. 

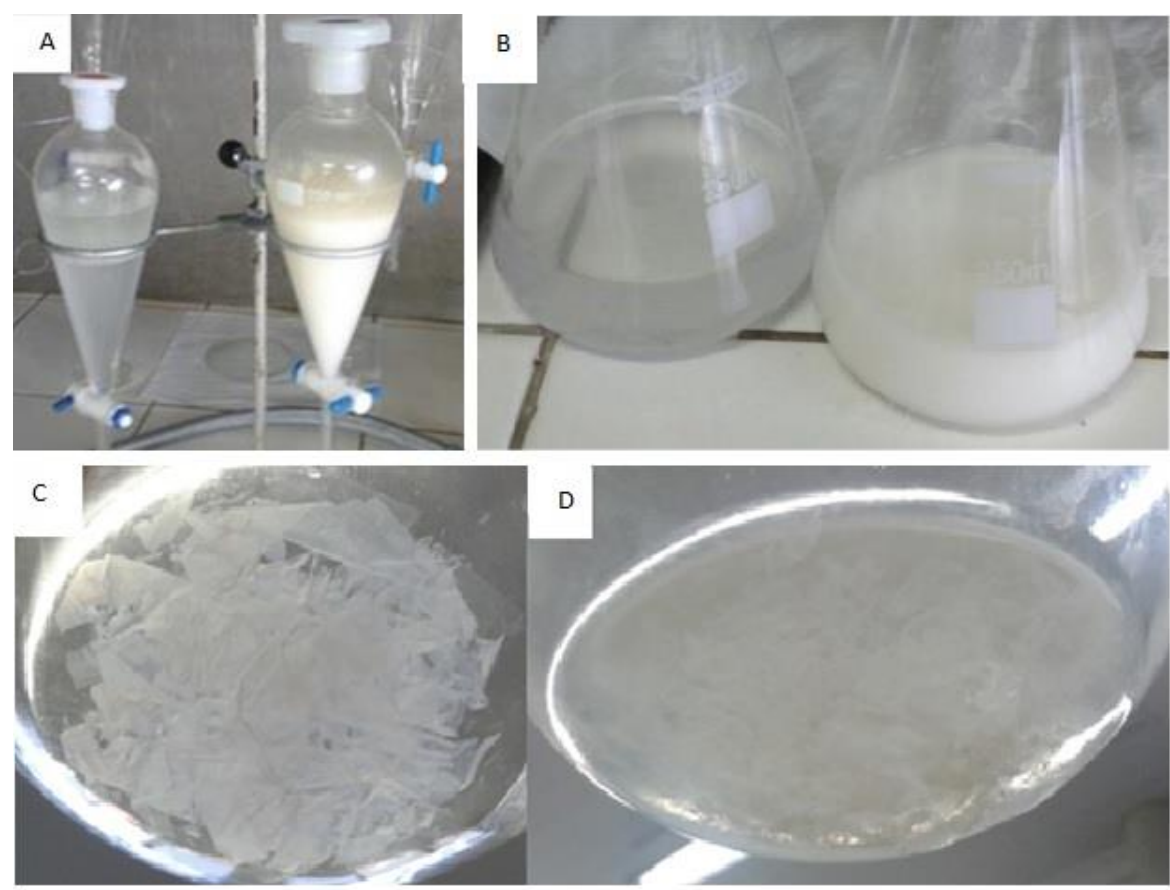

Figura 4 A, B, C e D - Passos da extração de biopolímero de células de E10, onde: (A) separação das fases da extração em funil de separação, (B) fase orgânica contendo biopolímero, (C) biopolímero extraído do cultivo em glicose, (D) biopolímero extraído do cultivo com hidrolisado.

\subsection{Análises do polímero obtido por absorção de UV-Vis em espectrofotômetro}

A análise do polímero extraído após cultivo da bactéria E10 em meio suplementado com hidrolisado da torta de tabaco ou glicose foi realizada por absorção de UV/VIS em espectrofotômetro. No gráfico da Figura 5 podem ser verificados os espectros do padrão comercial de $\mathrm{P}(3 \mathrm{HB})$ (linha em preto), do controle positivo (polímero de glicose, linha em verde) e do hidrolisado (polímero da torta de tabaco, linha em vermelho).

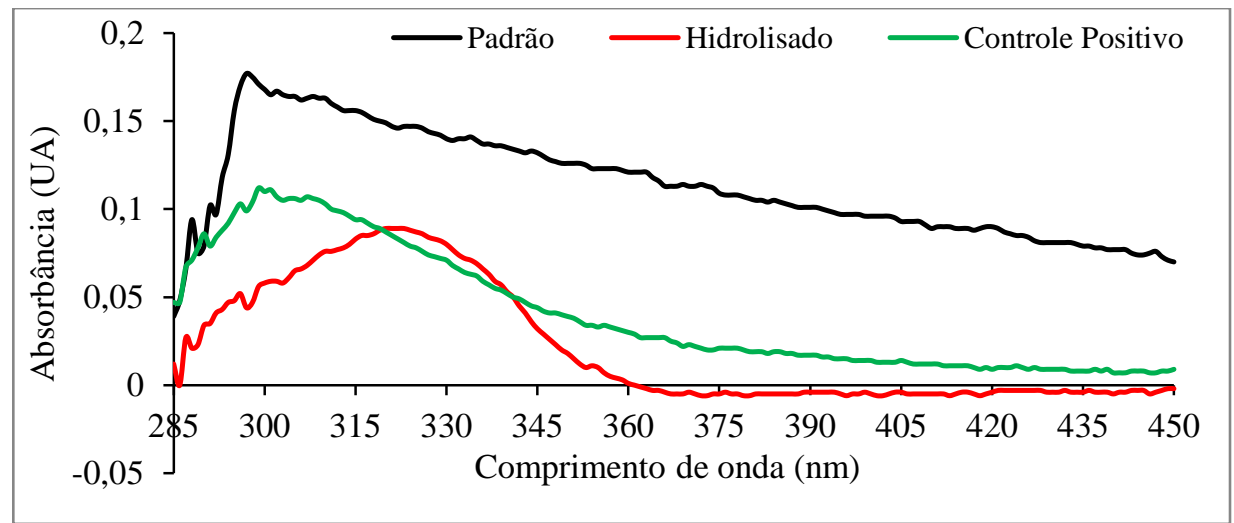

Figura 5 - Espectros das amostras de biopolímeros extraídos dos cultivos em glicose e em hidrolisado comparação com o espectro obtido de $\mathrm{P}(3 \mathrm{HB})$ comercial.

$\mathrm{Na}$ Figura 5 podemos verificar que o pico de absorbância do polímero produzido pela bactéria E10, quando glicose foi utilizada como substrato carbônico, 
aparece nos comprimentos de onda de 320 a 323 nm (0,089). Em 299 nm encontra-se a banda de absorbância $(0,112)$ do polímero produzido pela bactéria E10 quando utilizado o hidrolisado da torta de tabaco como substrato e em $297 \mathrm{~nm}$ a banda referente ao padrão comercial de $\mathrm{P}(3 \mathrm{HB})(0,177)$.

Na Figura 5 pode-se observar uma similaridade dos espectros de absorbância do padrão e da glicose, o que sugere que a bactéria controle tenha produzido o biopolímero $\mathrm{P}(3 \mathrm{HB})$. $\mathrm{O}$ espectro referente ao biopolímero produzido quando a E10 utiliza o hidrolisado da torta de tabaco, quando comparado ao padrão, apesar de similares, apresenta um deslocamento.

Este perfil de absorção, juntamente com o fato de o polímero obtido possuir características sugestivas de PHAs - positivo para coloração de Sudan Black, hidrofóbico e solúvel em clorofórmio -, sugere que a bactéria E10 esteja produzindo, além do $\mathrm{P}(3 \mathrm{HB})$, outra espécie de $\mathrm{PHA}$. No entanto a técnica não é capaz de caracterizar com precisão a espécie de PHA produzida.

\section{CONCLUSÃO}

Através da metodologia proposta foi possível o isolamento, triagem e identificação de produtores de $\mathrm{P}(3 \mathrm{HB})$ de maneira eficaz, rápida e barata. As bactérias obtidas junto a ETE da UNISC forneceram um bom material microbiológico a ser trabalhado, visto que se encontram em um ambiente com grande variabilidade de fontes energéticas, o que leva a uma maior adaptabilidade ao uso de diversos substratos por parte das bactérias.

A torta de tabaco, quanto a sua análise centesimal, mostrou-se rica em substratos energéticos como carboidratos, lipídios e proteínas, tendo assim um grande potencial de utilização em processos fermentativos. A utilização do hidrolisado obtido da torta de sementes de tabaco se mostrou aplicável na obtenção de $\mathrm{P}(3 \mathrm{HB})$, visto que se pode observar o acúmulo deste na forma de inclusões lipofílicas nas células bacterianas e, além disso, a quantidade elevada nos produtos extraídos. Com isso, podese utilizar um resíduo de baixo valor para a obtenção, mesmo que em escala reduzida, de um bioproduto com valor de mercado.

Uma análise mais específica (Cromatografia Gasosa acoplada à espectrometria de massas, Cromatografia Líquida de Alta Eficiência ou Ressonância Magnética

Nuclear de ${ }^{1} \mathrm{H}$ e ${ }^{13} \mathrm{C}$ ), para melhor caracterização do produto obtido, poderia confirmar com maior especificidade o tipo de polímero ou copolímero obtido, facilitando a 
compreensão da rota metabólica mais provável de utilização das fontes energéticas presentes no hidrolisado.

Os resultados, apesar de preliminares, indicam o potencial do hidrolisado da torta de tabaco na obtenção de biopolímeros. Outras análises serão feitas para caracterizar, avaliar a pureza e quantificar os biopolímeros obtidos, bem como a caracterização molecular dos isolados e sua identificação taxonômica.

\section{AGRADECIMENTOS}

Agradecemos à Fundação de Amparo à Pesquisa do Estado do Rio Grande do Sul (FAPERGS); ao Conselho Nacional de Desenvolvimento Científico e Tecnológico (CNPq); à Secretaria da Ciência, Inovação e Desenvolvimento Tecnológico (SDECT 209-2551/14-1); ao Ministério de Ciência, Tecnologia e Inovação (MCTI 01.0144.00/2010) e ao Parque Científico e Tecnológico Regional - TecnoUnisc.

\section{REFERÊNCIAS}

ALBUQUERQUE, M. G. et al. Mixed culture polyhydroxyalkanoate (PHA) production from volatile fatty acid (VFA)-rich streams: effect of substrate composition and feeding regime on PHA productivity, composition and properties. Journal of Biotechnology, n. 1, v. 151, p. 66-76, 2011.

ALBUQUERQUE, M. G. et al. Link between microbial composition and carbon substrate-uptake preferences in a PHA-storing community. The ISME Journal, n. 1, v. 7, p. 1-12, 2013.

ASHBY, R. D. et al. Bacterial poly(hydroxyalkanoate) polymer production from the biodiesel co-product stream. Journal of Polymers and the Environment, , n. 3, v. 12, p. 105-112, 2004.

BERLANGA, M. et al. Rapid spectrofluorometric screening of poly-hydroxyalkanoateproducing bacteria from microbial mats. International Microbiology, n. 2, v. 9, p. 95$102,2010$.

BHATTACHARYYA, A. et al. Utilization of vinasse for production of poly-3(hydroxybutyrate-co-hydroxyvalerate) by Haloferax mediterranei." AMB express, n. 1, v. 2, p. 1, 2012.

CECCHI, H. M. Fundamentos teóricos e práticos em análise de alimentos. 2. ed. Campinas: Editora da UNICAMP, p. 208, 2003.

CHOI, J.; LEE, S. Y. Factors affecting the economics of polyhydroxyalkanoate production by bacterial fermentation. Applied Microbiology and Biotechnology, n. 1, v. 51, p. 13-21, 1999. 
CHOI, J. I.; LEE, S. Y. Process analysis and economic evaluation for poly(3hydroxybutyrate) production by fermentation. Bioprocess Engineering, n. 6, v. 17, p. 335-342, 1997.

CIESIELSKI, S. et al. Plant oils as promising substrates for polyhydroxyalkanoates production. Journal of Cleaner Production, v. 106, p. 408-421, 2015.

DESOUKY, S. et al. Screening, Optimization and Extraction of Polyhydroxyalkanoates (PHAs) from Bacillus thuringienesis. Journal of Advances in Biology \& Biotechnology, n. 1, v. 1, p. 40-54, 2014.

DOUDOROFF, M.; STANIER, R. Role of poly-beta-hydroxybutyric acid in the assimilation of organic carbon by bacteria. Nature, n. 4673, v. 183, p. 1440, maio. 1959.

EL-SHEEKH, M. M. et al. Poly-3-hydroxybutyrate (PHB) production by Bacillus flexus ME-77 using some industrial wastes. Rendiconti Lincei, n. 2, v. 26, p. 109-119, jun. 2015.

HAAS, M. J. Improving the economics of biodiesel production through the use of low value lipids as feedstocks: vegetable oil soapstock. Fuel Processing Technology, n. 10, v. 86, p. 1087-1096, 2005.

HAYWOOD, G. W. et al. Accumulation of a Polyhydroxyalkanoate Containing Primarily 3-Hydroxydecanoate from Simple Carbohydrate Substrates by Pseudomonas sp. Strain NCIMB 40135. Applied and Environmental Microbiology, n. 11, v. 56, p. 3354-3359, 1990.

JENDROSSEK, D.; PFEIFFER, D. New insights in the formation of polyhydroxyalkanoate granules (carbonosomes) and novel functions of poly(3hydroxybutyrate). Environmental Microbiology, n. 8, v. 16, p. 2357-2373, 2014.

KHANNA, S.; SRIVASTAVA, A. K. Recent advances in microbial polyhydroxyalkanoates. Process Biochemistry, n. 2, v. 40, p. 607-619, fev. 2005.

KUNASUNDARI, B.; SUDESH, K. Isolation and recovery of microbial polyhydroxyalkanoates. Express Polymer Letters, n. 7, v. 5, p. 620-634, 2011.

LEGAT, A. et al. Identification of polyhydroxyalkanoates in Halococcus and other haloarchaeal species. Applied Microbiology and Biotechnology, n. 3, v. 87, p. 1119$1127,2010$.

LIAO, W. et al. Integrated Farm-Based Biorefinery. In: (Ed.). Biorefineries: Integrated Biochemical Processes for Liquid Biofuels, 2014. p.255-270.

LOPES, M. S. G.; ROCHA, R. C. S.; ZANOTTO, S. P. Screening of bacteria to produce polyhydroxyalkanoates from xylose. World Journal of Microbiology and Biotechnology, n. 10, v. 25, p. 1751-1756, 2009.

MAITY, S. K. Opportunities, recent trends and challenges of integrated biorefinery: Part I. Renewable and Sustainable Energy Reviews, n.3, v. 43, p. 1427-1445, 2015. 
MENG, D. C. et al. Engineering the diversity of polyesters. Current Opinion in Biotechnology, n. 1, v. 29, , p. 24-33, 2014.

MESQUITA, D. P. et al. Polyhydroxyalkanoate granules quantification in mixed microbial cultures using image analysis: Sudan Black B versus Nile Blue A staining. Analytica chimica acta, n. 1, v. 865, p. 8-15, 2015.

MIKKILI, I. et al. Isolation, Screening and Extraction of Polyhydroxybutyrate (PHB) producing bacteria from Sewage sample. Internacional Journal of Pharm TechResearch, n. 2, v. 6, p. 850-857, abr./jun.2014.

NIKEL, P. I. et al. New Recombinant Escherichia coli Strain Tailored for the Production of Poly (3-hydroxybutyrate) from Agroindustrial By-Products. Applied and Environmental Microbiology, n. 6, v. 72, p. 3949-3954, jun.2006.

OSTLE, A. G.; HOLT, J. Nile blue A as a fluorescent stain for poly-betahydroxybutyrate. Applied and Environmental Microbiology, n. 1, v. 44, p. 238-241, jul.1982.

PAL, A. et al. Optimization of Process Parameters for Maximum Poly (- beta-) hydroxybutyrate(PHB) Production by Bacillus thuringiensis IAM 12077. Polish Journal of Microbiology, n. 2, v. 58, p. 149-154, 2009.

PATTRA, S. et al. Bio-hydrogen production from the fermentation of sugarcane bagasse hydrolysate by Clostridium butyricum. International Journal of Hydrogen Energy, n. 19, v. 33 , p. 5256-5265, out.2008.

PRIETO, A. et al. A holistic view of polyhydroxyalkanoate metabolism in Pseudomonas putida. Environmental Microbiology, 2015.

RAMACHANDRAN, S. et al. Oil cakes and their biotechnological applications - A review. Bioresource Technology, n. 10, v. 98, p. 2000-2009, 2007.

REDDY, C. S. K; . Polyhydroxyalkanoates: an overview. Bioresource Technology, n. 2, v. 87, p. 137-146, 2003.

SANTIMANO, M.; PRABHU, N. N.; GARG, S. PHA Production Using Low-Cost Agro-Industrial Wastes by Bacillus sp. Strain COL1/Afi. Research Journal of Microbiology, n. 3, v. 4, p. 89-96, 2009.

SCANDOLA, M. et al. Polymer Blends of Natural Poly (3-hydroxybutyrate-co-3hydroxyvalerate) and a Synthetic Atactic Poly (3-hydroxybutyrate). Characterization and Biodegradation Studies. Macromolecules, n. 9, v. 30, p. 2568-2574, 1997.

SCHUCHARDT, U.; SERCHELI, R.; VARGAS, M. R. Transesterification of vegetable oils: a review. Journal of the Brazilian Chemical Society, n. 3, v. 9, p. 199210, 1998. 
SERAFIM, L. S. et al. Strategies for PHA production by mixed cultures and renewable waste materials. Applied Microbiology and Biotechnology, n. 4, v. 81, p. 615-628, 2008 .

SINGH, M. et al. Challenges and Opportunities for Customizing Polyhydroxyalkanoates. Indian Journal of Microbiology, n. 3, v. 55, p. 235-249, 2015.

SLATER, S. et al. Metabolic engineering of Arabidopsis and Brassica for poly (3hydroxybutyrate-co-3-hydroxyvalerate) copolymer production. Nature biotechnology, n. 10, v. 17, p. 1011-1016, 1999.

SOMLEVA, M. N.; PEOPLES, O. P.; SNELL, K. D. PHA Bioplastics, Biochemicals, and Energy from Crops. Plant Biotechnology Journal, n. 2, v. 11, p. 233-252, 2013.

SUDESH, K.; ABE, H.; DOI, Y. Synthesis, structure and properties of polyhydroxyalkanoates: biological polyesters. Progress in Polymer Science, n. 10, v. 25 , p. $1503-1555,2000$.

SUKAN, A.; ROY, I.; KESHAVARZ, T. Agro-Industrial Waste Materials as Substrates for the Production of Poly(3-Hydroxybutyric Acid). Journal of Biomaterials and Nanobiotechnology, n. 4, v. 5, p. 229, 2014.

TAN, G. A. et al. Start a esearch on Biopolymer Polyhydroxyalkanoate (PHA): A Review. Polymers, n. 3, v. 6, p. 706-754, 2014.

VALAPPIL, S. P. et al. Polyhydroxyalkanoates in Gram-positive bacteria: insights from the genera Bacillus and Streptomyces. Antonie van Leeuwenhoek, International Journal of General and Molecular Microbiology, n. 1, v. 91, p. 1-17, 2007.

STEINBÜCHEL, A.; VALENTIN, H. E. Diversity of bacterial polyhydroxyalkanoic acids. FEMS Microbiology Letters, v. 128, n. 3, p. 219-228, 1995.

WILLIAMSON, D.; WILKINSON, J. The Isolation and Estimation of the Poly- $\beta$ hydroxy-butyrate Inclusions of Bacillus species. Microbiology, n. 1, v. 19, p. 198-209, 1958.

XU, A. et al. Extraction and Characterization of PHB from Acidiphilium cryptum DX1-1. Journal Wuhan University of Technology, Materials Science Edition, n. 6, v. 25, p. 938-943, 2010.

\section{Como citar este documento:}

RIÇA, Larissa Brixner et al. Aproveitamento de torta do tabaco gerado na produção de biodiesel para a obtenção de bioplástico. Revista Jovens Pesquisadores, Santa Cruz do Sul, v. 6, n. 2, nov. 2016. ISSN 2237-048X. Disponível em: <https://online.unisc.br/seer/index.php/jovenspesquisadores/article/view/7523>. Acesso em: ... doi:http://dx.doi.org/10.17058/rjp.v6i2.7523. 